\title{
No Man is an Island: Social Coordination and the Environment
}

\author{
Karine Nyborg ${ }^{1}$
}

Accepted: 19 March 2020 / Published online: 27 March 2020

(c) The Author(s) 2020

\begin{abstract}
Humans are fundamentally social. Social activities require coordination, possibly leading to multiple equilibria in the form of self-reinforcing patterns of herd behavior. When alternative equilibria differ substantially with respect to environmental damage, they represent virtuous and vicious cycles from an environmental perspective. Such cycles can be sustained by network effects, social pressure to conform, or other mechanisms directly or indirectly yielding coordination benefits. Breaking the vicious cycles can be an important task for environmental policies. I present a stylized model of social coordination with environmental externalities, using it to discuss how environmental policies may help agents coordinate in more environment-friendly ways.
\end{abstract}

Keywords Environmental policy $\cdot$ Multiple equilibria $\cdot$ Social interaction $\cdot$ Tipping points

JEL Classification D10 · D62 - D91 · Q01 · Q50 · Q58

"No man is an island, entire of itself; every man is a piece of the continent, a part of the main" (Donne 1624, Ch. 17).

\section{Introduction}

Homo sapiens is a social animal. We like to spend time together, to share opinions, laughter, experiences and knowledge, to work together, to take part in social and professional networks. Joint activities require coordination, however; and since there are usually numerous alternative ways to coordinate, everyday life is teeming with multiple equilibria.

When choosing which conferences and seminars to attend, or whether to have lunch in the cafeteria or the department lunchroom, we consider who else will be there. When choosing which languages to learn, or which one to speak in a specific context, we consider what languages others are likely to understand. When choosing what type of car to purchase, or whether to purchase one at all, we consider what transportation infrastructure

Karine Nyborg

karine.nyborg@econ.uio.no

1 Department of Economics, University of Oslo, P. O. Box 1095, Blindern, 0317 Oslo, Norway 
is likely to be present in the near future, such as gas stations, electrical charging facilities, bus and metro lines-where some options will presumably be better developed if others are demanding their availability. When organizing our daily lives-housing, work, family responsibilities - we adapt to others' expected behaviors, trying to facilitate convenient and pleasant interaction.

This need for social coordination implies external effects: the individual benefits of adopting a specific behavior are affected by the behaviors of others, often in ways not internalized by market prices. If these social externalities are sufficiently prominent, multiple equilibria can result — of which some may involve heavier burdens on the natural environment than others.

If there is both a 'green' and a 'brown' Nash equilibrium, each can be stable and selfreinforcing, thus representing, from an environmental point of view, virtuous or vicious cycles. In such cases, if starting from a 'brown' equilibrium, policy can potentially play an important role in helping the economy coordinate on more environment-friendly solutions (Rege 2004; Nyborg and Rege 2003; Nyborg et al. 2006, 2016; Nyborg 2018).

Below, I discuss why social coordination is an important concern for environmental economics and environmental policy, illustrating the main ideas by means of a simple formal model. I begin by suggesting one possible reason why standard welfare economics, while certainly useful in many ways, may have diverted economists' attention away from social externalities and social coordination (Sect. 2). I then explain what I mean by social coordination, elaborating on some examples (Sect. 3), before presenting a highly stylized formal model (Sect. 4). This model is then used to discuss how environmental policy can play an important role in helping agents coordinate on socially preferred equilibria (Sect. 5). Finally, I sum up my conclusions (Sect. 6).

\section{The Benchmark Model of Welfare Economics: Social Isolation}

Since the ground-breaking contributions of Ostrom (1990) and her collaborators, environmental and resource economists have increasingly explored social interaction explicitly in their analyses (e.g., Rege 2004; Johansson-Stenman and Martinsson 2006; Allcott 2011; Dasgupta and Ehrlich 2013; Richter and Grasman 2013; Dasgupta et al. 2016; Schlüter et al. 2016; Farrow et al. 2017; Pal et al. 2017; Carattini et al. 2017; Czajkowski et al. 2017). Still, given the vital role social interaction plays in human lives (more on this below), one might be tempted to say that the research field has been remarkably slow to take off.

Substantial parts of environmental economics is based on welfare economics, for which the standard benchmark model is the perfectly competitive market-a hypothetical situation completely free of market failure, providing the basis for the two fundamental welfare theorems. It is well-known that this benchmark model precludes shared natural environments (which would have represented public goods), thus also ignoring environmental despoliation. An aspect of the perfectly competitive market that has received surprisingly little attention in the economics literature, however, is that this model implicitly also precludes normal social contact between the economic agents.

When people meet, they cannot avoid influencing each other in a whole range of waysincluding non-contracted ones: beauty and ugliness, aggression and kindness, liking and irritation, stupidity and arrogance, odors and noise. To prevent such externalities in a perfectly competitive market, economic agents would essentially have to be completely 
isolated from each other-at least until fully specified trade contracts, governing all aspects of joint surroundings and interpersonal encounters, were established and agreed upon by every agent involved (Nyborg 2019). ${ }^{1}$

To be part of something is fundamental to human beings. When individuals are isolated, deprived of normal sensory stimuli, they are likely to soon start hallucinating, to struggle to pursue ordinary logical thought, and to lose their sense of time as well as their usual conception of a self (Zuckerman and Cohen 1964; Goldberger 1966; Sireteanu et al. 2008; Ringach 2009). Yet, this is the situation implied by the standard benchmark model.

Of course, the perfectly competitive market was hardly ever intended as an accurate description of the real world. Its value lies primarily in helping clarify why and how real markets, with all their departures from the benchmark model, should not be expected to work efficiently. By using the benchmark model routinely as one's starting point for environmental policy analysis, however, one may become accustomed to disregarding social ties between people in analytical work-which may neither promote awareness of the nonmarket interconnectedness of human societies, nor provide adequate training in formal analysis of its economic and environmental implications.

When searching for the causes of and remedies for environmental deterioration, economists need to look beyond the idea of isolated agents connected by markets. Social interaction is not just another good or service that may be preferred more or less strongly; like the natural environment, it shapes the very context of our lives, fundamentally affecting behaviors. A lack of social relationships is associated with substantially increased mortality risk (Berkman and Syme 1979; House et al. 1988; Eisenberger and Muscatell 2013). Widowhood is associated with depression (Umberson et al. 1992). Unemployment reduces self-reported happiness substantially, apparently mainly linked to non-pecuniary distress (Oswald 1997). The brain processes involved in social pains and pleasures, like feeling rejected or included, are highly similar to the brain processes involved in physical pains and pleasures caused by, e.g., physical injury or the pleasure of enjoying good food (Eisenberger et al. 2003; Eisenberger and Muscatell 2013; Lieberman 2013). Neuroscientists have found that when thinking of nothing in particular, the mind tends to wander to social life-the 'default network' activated in the brain when resting being virtually identical to the network activated by social cognition (Lieberman 2013, Ch. 2). Humans are fundamentally social—and should be acknowledged as such in the economic analysis. In particular, social coordination may involve policy options of interest to environmental economists.

\section{What is Social Coordination?}

When using the term 'social coordination', what I have in mind are the Nash equilibria of $N$-person coordination games - the various situations in which we adapt to each other's behaviors and plans such that, given others' strategies and beliefs, no-one has reason to change their strategies and beliefs: "everyone wants to play their part given the expectation that everyone else will continue to play theirs" (Young 1998, p.821). I am particularly

\footnotetext{
1 A perfectly competitive market would depart so dramatically from the world as we know it that grasping the full implications is extremely hard. Being a fiction writer as well as an economist, I spent several months trying to do so-which, to me, turned out to be an eye-opener: see Nyborg (2019, Part II) for a science fiction story of two young economists travelling to the perfectly competitive market for their honeymoon.
} 
interested in patterns of behavior occurring repeatedly and routinely by many individuals, whereby common knowledge of current customary behavior is likely to shape expectations, thus serving as a coordination device.

The key for multiple social coordination equilibria to arise is that the net individual benefits (broadly defined) of adopting a specific behavioral pattern increase sufficiently in the share of others adopting the same behavioral pattern. Expectations can then become self-fulfilling: if a certain behavior is generally expected, the behavior is generally chosen precisely because it is expected (Young 2015).

The individual benefits of adopting a behavior may increase in others' adoption for a variety of reasons. Practical and logistical considerations may imply a direct need of coordination: meetings dissolving into nothing unless participants convene at the same time and place; teamwork being successful only if co-workers adhere to the same work plan; research conferences being interesting only if attended by others in one's research field; communication being effective only if using a language each understands. For common, recurring routine behaviors involving such coordination needs, conventions may develop: "a pattern of behavior that is customary, expected and self-enforcing [...]. [W] may define a convention as an equilibrium that everyone expects in interactions that have more than one equilibrium" (Young 1996, p. 105; see also Sugden 1989). If you know that driving on the left is customary in the country you are visiting, you keep to the left. Knowing that English is the customary language of international scientific journals, you write your research papers in English.

Coordination benefits may also arise as a result of social approval and disapproval, either directly (as with conformity norms) or more indirectly (see below). Game theorists often view social norms as customarily played equilibria of $\mathrm{N}$-person coordination games, enforced through social sanctions and/or social approval (see Sugden 1989; Bicchieri 2006; Gintis 2010; Young 2015). ${ }^{2}$ Nyborg et al. (2016, p.42) define a social norm as "a predominant behavioral pattern within a group, supported by a shared understanding of acceptable actions and sustained through social interactions within that group".

For example, Nyborg and Rege (2003) demonstrate how both a social norm allowing indoor smoking and a norm disallowing the same may represent stable equilibria. Smokers choose whether to smoke outdoors or indoors, in the latter case exposing others to tobacco smoke. Non-smokers react negatively to being exposed to passive smoking, more so if they are not used to it. Hence, if indoor smoking is uncommon, indoor smokers face strong social reactions from non-smokers, who are not accustomed to it; this makes smokers more inclined to bring their cigarettes outdoors, completing the virtuous cycle (viewed from non-smokers' perspective). A vicious cycle could also be self-reinforcing, however: if indoor smoking is common, non-smokers' reactions are weak, making indoor smoking relatively pleasant-keeping smokers indoors (Fig. 1). ${ }^{3}$

Each equilibrium illustrated in Fig. 1 involves herd behavior by smokers, even though they are not assumed to have preferences for conformity as such; the social coordination

\footnotetext{
${ }^{2}$ Following Cialdini et al. (1991), psychologists typically use the concept slightly differently, distinguishing between descriptive and injunctive social norms (conceptions of what others do and think one ought to do, respectively), but without requiring that norms represent equilibria (see Nyborg 2018 for a discussion).

3 In the early 1980's, I worked as an untrained nurse assistant in an Oslo hospital. During staff meetingswhich took place in a small, crowded room located few meters from patients' rooms - about half of the present nurses would typically smoke. Such behavior was considered completely normal; if fellow nurses were bothered, this was viewed as one of the sad facts of life.
} 

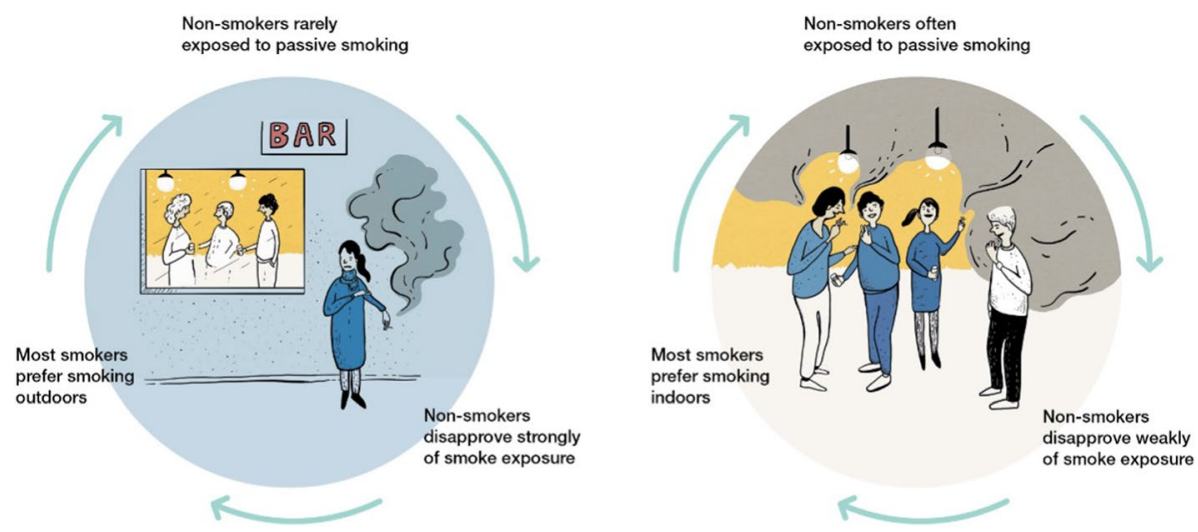

Fig. 1 Virtuous and vicious cycles of considerate smoking behavior. (Artwork: Elsa Wikander, Azote/Beijer Institute of Ecological Economics.)

benefits are caused by non-smokers' adaptation and the associated variation in their negative reactions.

The model also has a third Nash equilibrium, namely the situation where non-smokers' reactions are exactly strong enough to make smokers indifferent between indoors and outdoors smoking; this equilibrium is unstable, representing a tipping point.

Using evolutionary game theory, Nyborg and Rege (2003) demonstrate that, starting from the non-consideration equilibrium, a smoking regulation can help push the economy past the tipping point, thus establishing a new, stable norm of considerate smoking behavior. If a formal and strictly enforced regulation is introduced, prohibiting smoking in certain places (such as public transport and workplaces), this makes non-smokers less used to passive smoking, thus strengthening their negative reactions to indoor smoking in unregulated areas. If the regulation is wide-reaching enough, the non-consideration norm ceases to be an equilibrium. ${ }^{4}$ Over time, more and more smokers become considerate-until a stable norm of considerate smoking behavior is firmly established, even in unregulated places like private homes. ${ }^{5}$ Thus, although a formal regulation of indoor smoking in private homes may be politically infeasible and very hard to enforce, a much more limited regulation might do the job through its effect on social norms.

What if the smoking regulation is later abolished? The initial no-consideration situation would then again become an equilibrium. Nevertheless, there is little reason to expect the economy to revert back to its previous state: the new full consideration state is, after all, an equilibrium too, and there is no particular reason why the economy would stray away from it.

\footnotetext{
${ }^{4}$ In the static part of the Nyborg and Rege (2003) model, 'equilibrium' means Nash equilibrium; in the dynamic analysis we use the concept of asymptotically stable states.

5 Survey data from 1999, reported in Nyborg and Rege (2003), indicates that abrupt and substantial behavioral changes did indeed occur soon after the introduction of Norwegian smoking restrictions in 1988. In 1999 , less than $2 \%$ of smokers reported to usually smoke indoors without asking for permission when visiting friends; $37 \%$, however, said they usually did so 10-15 years earlier. 12 percent of non-smokers reported that their smoking guests would usually smoke indoors without asking; as much as 74\% claimed that this was smoking guests' most common behavior 10-15 years earlier.
} 
Similarly, habitual adaptation may make people like the foods they are used to, or prefer the indoor temperature level they are usually exposed to, possibly producing social coordination benefits which, if sufficiently strong, can lead to multiple coordination equilibria.

Network effects is also a possible source of social coordination benefits. According to Liebowitz and Margolis (1994, p. 135), network effects are present when "the net value of an action (consuming a good, subscribing to telephone service) is affected by the number of agents taking equivalent actions". ${ }^{6}$ For example, if few others drive electric cars, charging stations are likely to be few, making the purchase of an electric car unattractive; if, instead, most other cars are electric, gas stations may be scarce, making the purchase of a gas-fueled car unattractive. While network effects are often considered a purely economic rather than social phenomenon, note that by replacing the word 'value' by 'benefit' and using slightly different examples-learning a language, smoking indoors-Liebowitz and Margolis' explanation could equally well serve as a description of the social coordination benefits supporting conventions or social norms.

Drawing a clear distinction between conventions, social norms and multiple equilibria caused by network effects may not be easy, and is not my concern here. My point is rather that a variety of mechanisms, direct or indirect, can cause individual benefits of a behavior (or behavioral pattern) to increase in the share of others adopting the same behavior (or behavioral pattern). In a given context, several such mechanisms can be at play simultaneously. Indeed, social feedback mechanisms can arise endogenously (Andreoni et al. 2020): when coordination benefits are present due to, e.g., logistic and/or habitual factors, those deviating from customary behaviors may be socially sanctioned for limiting the coordination benefits obtained by others, which strengthens the initial coordination benefits. Also, internalized moral motivation can be socially learned, shaped by what one observes others doing (Brekke et al. 2010).

Customary diets may provide an example of several coordination benefits being present simultaneously. If most others are meat-eaters, it is cumbersome to be a vegetarian, and vice versa (Nyborg et al. 2016): cooking for shared meals can be more complicated, requiring more effort; rejecting the foods others enjoy may be seen as a sign of social distance, triggering negative emotional reactions; products needed to cater for those keeping a diverging diet may be poorly supplied in grocery stores and restaurants; for such reasons, people keeping a diverging diet may be less likely to be invited to social occasions involving shared meals, and may be frowned at when sharing meals. ${ }^{7}$ Nevertheless, other, socially non-contingent factors also typically matter, such as costs, nutritional content, individual health concerns, and socially independent aspects of personal taste; such factors may be independent of or even counteract social coordination benefits. Again, the key for multiple equilibria to arise is whether the net individual benefit of adopting one behavior rather than the other is increasing, and sufficiently so, in the share of others adopting the same behavior (Fig. 2). Note that if the practical inconvenience of keeping a diverging diet

\footnotetext{
${ }^{6}$ Liebowitz and Margolis (1994) reserve the term 'network externalities' to the case where network effects are not being fully internalized in market equilibrium. Klemperer (2008) distinguish between direct network effects, arising when individual users' payoff increase as a direct result of more others adopting the good, and indirect network effects, arising when such complementarities in users' payoff are caused by the effect of increased adoption on a related market.

7 Again, habitual adaptation matters. If diet preferences were fully flexible (and allergies and the like were no problem, a meat-eater joining a group of vegetarians for dinner may just happily, for once, forego meat. If tastes develop over time, however, making us prefer the diets we are used to, flexibility is more limited.
} 

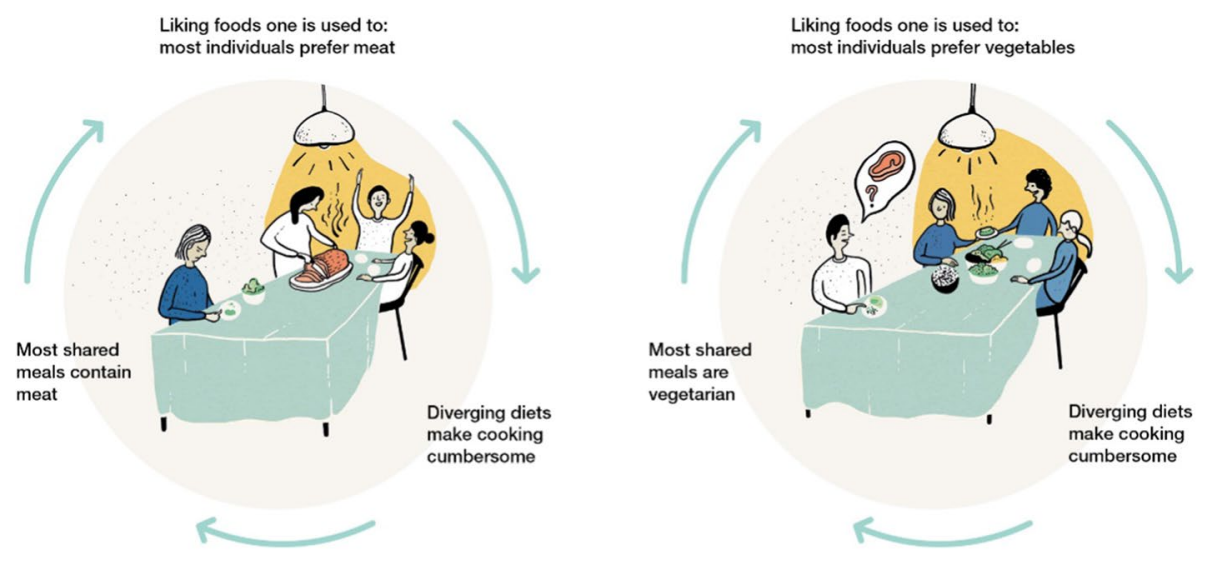

Fig. 2 Virtuous and vicious cycles of eating habits. (Artwork: Elsa Wikander, Azote/Beijer Institute of Ecological Economics.)

does not suffice on its own, multiple equilibria could still be enforced if those keeping an uncommon diet face social sanctions in addition to the practical inconvenience.

The eating habit example illustrates an important point: while the individual need for social coordination may arise from reasons unrelated to environmental quality, one equilibrium can still cause more environmental damage than the other. Individuals' reasons for choosing a vegetable-based diet may be entirely unrelated to concerns for environmental protection, animal welfare, or even own health: people may simply conform to customary, prevalent eating habits in order to share convenient and pleasant meals with others, making environmental impacts an unintended side-effect (Nyborg et al. 2016). Similarly, in the car purchase example, multiple equilibria are caused by network effects impacting the transportation services delivered by the car, the environmental consequences arising as a byproduct the customer may or may not care about (and may or may not experience social sanctions or approval for).

When looking for ways to solve a specific environmental problem, thus, an important question is whether one is actually faced with a coordination game associated with environmentally detrimental herd behavior. If so, the next question is how the vicious cycle can be broken (Nyborg et al. 2016). I return to this in Sect. 5; first, however, establishing a simple formal model may be helpful.

\section{Modelling Environmental Impacts of Social Coordination}

\subsection{The Model Set-Up}

Consider a large population $P$. Let the utility $U_{i}$ of each individual $i \in P$ depend on a standard private consumption good $x_{i}$; a private good $s_{i}$ associated with social coordination benefits (for example, social approval); and environmental quality $E$, a pure public good:

$$
U_{i}=x_{i}+s_{i}+\beta E
$$

where $\beta>0$ (linearity is assumed for simplicity). The individual's benefit of the socially interdependent good $s_{i}$ depends on a discrete choice $z_{i} \in\{g, b\}$ that $i$ makes between a 
green $\left(z_{i}=g\right)$ and a brown $\left(z_{i}=b\right)$ alternative. Let $q$ be the share of the population choosing green $(0 \leq q \leq 1)$, and let the household production function for $s_{i}$ be given by

$$
s_{i}=s\left(z_{i}, q\right)=\left\{\begin{array}{lll}
G^{0}+q K & \text { if } & z_{i}=g \\
B^{0}+(1-q) k & \text { if } & z_{i}=b
\end{array}\right.
$$

where $G^{0}, B^{0}, K \geq 0$, and $k \geq 0$ are constants. $G^{0}$ is the individual benefit of choosing green if no-one else does so, while $K$ is the social coordination benefit obtained in addition if everyone else chooses green too. Similarly, $B^{0}$ is the benefit of being the only one choosing brown, while $B^{0}+k$ is the benefit of choosing brown if everyone else does so. $K$ and $k$ are assumed weakly positive in order to focus on coordination equilibria involving herd behavior. ${ }^{8,9}$ Each individual has an exogenous income $Y \geq 0$, assumed identical for all for simplicity. Let $c^{g}<Y$ and $c^{b}<Y$ denote the exogenously fixed costs of making the green or brown choice, respectively. The individual's budget constraint ${ }^{10}$ is given by

$$
Y= \begin{cases}x_{i}+c^{g} & \text { if } z_{i}=g \\ x_{i}+c^{b} & \text { if } z_{i}=b\end{cases}
$$

Finally, assume that environmental damage is proportional to the share choosing brown, such that

$$
E=E^{0}-\gamma(1-q),
$$

where $E^{0}$ is an exogenous supply of environmental quality, while $\gamma>0$.

Assume that $i$ considers others' contributions to $E$ exogenously fixed, and also considers any environmental effects of her own behavior to be negligible; that is, $i$ considers $E$ fixed. ${ }^{11}$ Further, let the population be large enough that the individual can also reasonably regard $q$ as exogenous, independent of her own choice.

Individual $i$ chooses green if her utility of doing so exceeds her utility of choosing brown, which is the case if $U(g)-U(b) \geq 0$ when considering $E$ fixed. ${ }^{12}$ Equations (1)-(3) above imply that this holds whenever

$$
G^{0}+q K-c^{g} \geq B^{0}+(1-q) k-c^{b} .
$$

If eq. (5) holds for $q=1$, i.e., if

\footnotetext{
${ }^{8}$ If factors involving negative coordination benefits are present (such as a preference to stand out from others, or increasing marginal costs), the implicit assumption is thus that factors involving positive coordination benefits dominate. Note that for some coordination problems, such as driving on the left or the right, coordination benefits may be strongly convex rather than linear.

9 Since only the utility difference between green and brown matters for behavior, a behaviorally equivalent assumption would be that $s_{i}=Z^{0}+q K^{\prime}$ when $z_{i}=g$ and 0 otherwise, where $Z^{0}=G^{0}-B^{0}-k$ and $K^{\prime}=K+k \geq 0$. Specification (3) is chosen because I find it intuitively easier to apply to various specific examples; see the discussion below.

10 If $Y$ is interpreted as inclusive income, $c^{g}$ and $c^{b}$ can include costs in terms of time or effort. For details, see Czajkowski et al. 2017, Sect. 3 and footnote 3.

11 If the individual instead takes into account the effect on the environment of her own choice, this environmental benefit must be added to the utility of choosing green throughout the discussion below; apart from this, conclusions would not change.

12 Here, $U(g)=U_{i} \mid\left(z_{i}=g\right)$, and $U(g)=U_{i} \mid\left(z_{i}=g\right)$.
} 


$$
G^{0}+K-c^{g} \geq B^{0}-c^{b},
$$

the situation where everyone chooses green $\left(z_{i}=g\right.$ for all $\left.i\right)$ is a Nash equilibrium. Similarly, the situation where everyone chooses brown $\left(z_{i}=b\right.$ for all $\left.i\right)$ is a Nash equilibrium if $U(g)-U(b) \leq 0$ when $q=0$, i.e., if

$$
G^{0}-c^{g} \leq B^{0}+k-c^{b} .
$$

If both Eqs. (6) and (7) hold with strict inequality, i.e., if

$$
0<\frac{\left(B^{0}-c^{b}\right)-\left(G^{0}-c^{g}\right)+k}{K+k}<1,
$$

there are three Nash equilibria in the model: the situation where $z_{i}=g$ for all $i$, the situation with $z_{i}=b$ for all $i$, and the situation where each individual is exactly indifferent between the green and brown choice, characterized by $q=q^{*}$ (where $1>q^{*}>0$ ) given by

$$
q^{*}=\frac{\left(B^{0}-c^{b}\right)-\left(G^{0}-c^{g}\right)+k}{K+k} .
$$

Although the model is static, the equilibrium where $q=q^{*}$ can be considered unstable in the following sense: if the share choosing green is just slightly higher than $q^{*}$, everyone prefers green; if it is just slightly below $q^{*}$, everyone prefers brown. In this comparative statics sense, $q^{*}$ is a tipping point, while $q=0$ and $q=1$ are both stable equilibria. ${ }^{13}$

When Eq. (8) holds, the above is a coordination game. Being static, the model as such provides no clear-cut prediction regarding equilibrium selection. However, if the context is interpreted as $z_{i}$ being a commonly occurring routine behavior, knowledge of current customary behaviors is likely to strongly affect expectations. If there are substantial social coordination benefits, and the brown (green) choice is generally known to be customary, it seems reasonable to expect others to keep to that custom. In the terminology of Schelling (1960), knowledge of the custom makes the brown (green) equilibrium a focal point.

\subsection{Examples and Interpretations}

Some examples may illustrate. Consider first a simple, symmetric conformity norm, where individuals are frowned at for being different than most others, e.g., by wearing a different clothing style. Assume that social sanctions arise as costless, spontaneous, but observable reactions to others' behavior, allowing us to focus on the choice between the green and brown alternatives, while disregarding any conscious choice of whether or not to provide sanctions. If production and/or final disposal cause more pollution for one clothing style (i.e. plastic-based materials) than the other, while non-social benefits of the styles are otherwise identical, this corresponds to $K=k$ and $G^{0}=B^{0}$ (Fig. 3, Panel a). In this case, Eq. (9) implies that $q^{*}=\frac{\left(c^{g}-c^{b}\right)}{2 k}+\frac{1}{2}$. Thus, if the green and brown choices are equally costly, $q^{*}=\frac{1}{2}$. In particular, note that even if the brown choice is more costly, everyone choosing brown can well be a (stable) Nash equilibrium.

\footnotetext{
${ }^{13} q=q^{*}$ can be obtained either by everyone using a mixed strategy, choosing green with a probability $q^{*}$, or by a share $q^{*}$ of the population using the pure strategy $z_{i}=g$ and the rest using the pure strategy $z_{i}=b$.
} 


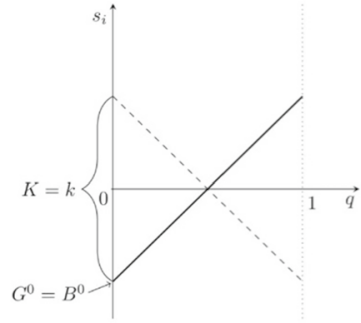

(a)

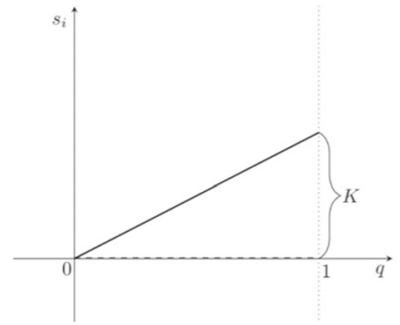

(b)

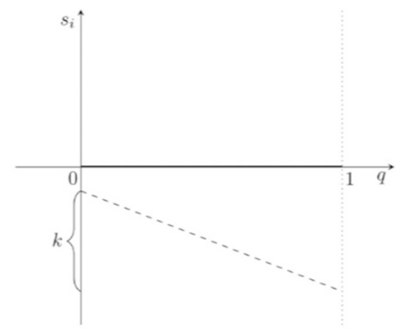

(c)

Fig. 3 Individual benefits of the socially interdependent good $s_{i}$ as a function of $\boldsymbol{q}$, the share choosing green. Dotted lines show $s_{i}$ if choosing brown, bold lines show $s_{i}$ if choosing green. a Symmetric coordination norm, b green choosers approving of each other, $\mathbf{c}$ sanctions for choosing brown stricter when brown choice is uncommon

Another interpretation of this same analysis is that $s_{i}$ denotes individual benefits of purchasing a car, where $z_{i}=g$ indicates an electric car and $z_{i}=b$ a fossil-fueled one, provided that each type of vehicle provides similar non-environmental, socially non-contingent benefits $\left(G^{0}=B^{0}\right)$ and that network effects are equally strong for the two types of cars $(K=k)$. Differences in individual, socially non-contingent benefits provided by each alternative can be taken into account by assuming $G^{0} \neq B^{0}$, while asymmetric social coordination benefits would imply $K \neq k$.

Approval or sanctions may be more strongly asymmetric. For example, let $s_{i}$ be social approval, and let those making the green choice approve of each other when they meet, while those making the brown choice neither give nor receive approval. This can be described by $K>0$ and $k=B^{0}=G^{0}=0$ (Fig. 3, Panel b). The existence of both a green and a brown Nash equilibrium now requires $0<\frac{c^{g}-c^{b}}{K}<1$ [ref. Eq. (8)]. If the brown choice is strictly more costly, there is no brown Nash equilibrium in this case.

In Nyborg and Rege's (2003) analysis of smoking norms, sanctioning of indoor smokers is decreasing in their share, while outdoor smoking triggers neither social sanctions nor approval. If $z_{i}=b$ denotes indoor smoking and $z_{i}=g$ is smoking only outdoors, this corresponds to $B^{0}<0, k>0$, and $G^{0}=K=0$ in the current model (Fig. 3, Panel c). Moreover, assume that there is a cost involved in smoking outdoors but not indoors, so $c^{g}>0$ and $c^{b}=0$. Using this in Eq. (8) and rearranging, we see that both the considerate and non-considerate social norms represent Nash equilibria provided that $B^{0}+k>-c^{g}>B^{0}$. That is, for indoor smoking to be a stable norm, the individual net benefit of smoking indoors if everyone else does so $\left(B^{0}+k\right)$ must be higher than the individual net benefit of being the only one smoking outdoors $\left(-c^{g}\right)$; moreover, for outdoor smoking to be a stable norm, the net individual benefit of smoking outdoors when everyone does so $\left(-c^{g}\right)$ must be higher than the net individual benefits of being the only one smoking indoors $\left(B^{0}\right)$.

As mentioned above, social sanctions against deviant behaviors may arise endogenously (Andreoni et al. 2020; Ostrom 1990), so several sources of coordination benefits may well be present simultaneously. For example, in a society of meat-eaters, vegetarians may be frowned at for being 'difficult'. Although disregarded in the formal model, factors counteracting the coordination benefits may also be present, such as crowding effects, contributing towards a lower or negative $K$ and/or $k$. In applied analyses, such factors must of course also be taken into account. 
I have argued above that social coordination benefits are likely to be widespread. I must add a note of caution, however. The presence of social coordination benefits does not in itself guarantee the existence of multiple equilibria. Even with homogeneous individuals, such benefits must be substantial enough to outweigh other motives such as socially noncontingent taste and cost differences. In addition, extreme multiple equilibria arise more easily with homogeneous than with heterogeneous individuals. Thus, the simple model above may be said to exaggerate the case for social coordination with multiple extreme equilibria. If individuals' preferences or constraints differ, their 'individual tipping points', i.e., the $q$ making the individual indifferent, are likely to differ too. This may make equilibria less extreme, involving some individuals deviating from customary behaviors even in the polar Nash equilibria (Nyborg and Rege 2003) — or the multiplicity of equilibria may disappear altogether (Efferson et al. 2020).

\subsection{Welfare Analysis}

Assume now that utility as given by Eq. (1) can be interpreted as a measure of individual well-being, and that the population $P$ includes everyone relevant for social welfare judgements. ${ }^{14}$ The green equilibrium is then welfare and Pareto superior to the brown equilibrium if

$$
\beta \gamma+G^{0}+K-c^{g} \geq B^{0}+k-c^{b},
$$

i.e., if the net social benefit of the green alternative being chosen by all exceeds the net social benefit of the brown alternative being chosen by all.

Note that since individuals are identical, there are no conflicting interests in the model. In real life, preferences, needs, opportunities and initial resources differ, implying that a switch may be beneficial to some but detrimental to others. If so, the concepts of welfare and Pareto improvements may not coincide, and welfare judgements will typically depend on the social welfare function.

Further, the static comparison in Eq. (10) does not consider transition costs involved in tipping the economy from one equilibrium to another. A formal analysis of the latter would require an explicitly dynamic model, which may be done, for example, using evolutionary game theory (Weibull 1995; Young 2015). A transition period during which behaviors are poorly coordinated could involve substantial costs in terms of lost coordination benefits (and associated social conflict), particularly so if coordination benefits were strongly convex rather than linear as assumed above. ${ }^{15}$ Further, a switch to a new equilibrium can reduce the value of investments related to previous behavioral patterns, making durable goods, technology or knowledge obsolete or less useful. For example, if a transition to electric cars make gas stations scarce, this would reduce the value of the existing stock of gas-fueled cars. Similarly, if customary eating habits change from meat-based to

\footnotetext{
14 Note that in the smoking example above, the descriptive analysis focuses on smokers' behavior, while non-smokers enter the model only through their assumed spontaneous (not chosen) social feedback. Hence, in this case $P$ must be regarded as the population of smokers, while non-smokers' welfare would also of course be relevant for welfare judgements. For example, one may assume that non-smokers' displeasure of passive smoking is proportional to or increasing in the social feedback $B^{0}+(1-q) k$, adding this displeasure to smokers' private utility and the environmental effects.

15 Note, however, that while patterns of social coordination can be very stable over time, changes can happen quite abruptly once they occur (see Young 2015).
} 
vegetarian, cooks may need to become familiar with new cooking methods and recipes, while part of their previous knowledge becomes obsolete. The literature on network effects use dynamic approaches to study such phenomena, exploring how market diffusion of a socially superior product may be characterized by excess inertia (users are inefficiently reluctant to switch) or excess momentum (users are inefficiently eager to switch) (Farrell and Saloner 1985, 1986; Greaker and Midttømme 2016). ${ }^{16}$

\section{The Role of Environmental Policy}

While spontaneous switching to a socially preferred coordination equilibrium can occur, the stability of the prevailing equilibrium may well prevent this from happening. In a recent lab experiment, Andreoni et al. (2020) find that when changes in the underlying payoff structure cause the current equilibrium to become welfare inferior, many groups do not switch to the superior one; moreover, when individuals can choose to sanction others, they tend to choose high sanctions for violators of the current norm, causing persistence of welfare inferior equilibria. Knowledge about others' intentions and preferences help trigger change; nevertheless, Andreoni et al. (2020) find that rapid information feedback about others' behavior can discourage switching, by confirming that others still adhere to the existing norm. ${ }^{17}$

As illustrated by the smoking regulation case discussed earlier, however, public policy might help move the economy from one equilibrium to another (Rege 2004; Nyborg et al. 2016; Nyborg 2018; Andreoni et al. 2020). While environmental policies have traditionally focused on changing the choice set and relative prices, a potentially important task for environmental policy is thus to help economic agents coordinate in more environmentfriendly ways.

Social externalities represent a market failure in addition to the environmental externalities. For example, due to network effects, each customer purchasing a new electric car helps making electric cars more attractive to future customers. Intuitively, if the economy is stuck in a brown equilibrium, pushing the economy past the tipping point can induce long-lasting reductions in environmentally damaging behaviors, which may justify quite strong temporary policies (Greaker and Midttømme 2016).

There are two main ways that policy may intervene: by changing the incentives and/or the choice set, making the current situation cease to be an equilibrium; or by changing prevailing expectations, thus changing which equilibrium is selected.

Consider the following situation. The local school is not far away from your house, within easy reach by bike. You would have liked your kids to bike or walk to school together with the neighboring kids: it would be good for their health, bolster their friendship, and be easier for you than bringing them by car. Due to heavy car traffic around the school, however, you find it too risky; hence you drive them. If the heavy traffic is caused by other parents driving their kids to school, by the same reasoning as yours, this might

\footnotetext{
16 "The possible inefficiencies arise from two externalities in the model. First, when a firm switches, its rival loses some network benefits while they are using incompatible technologies, and the switching firm ignores this in its calculations. Second, even if users unanimously favor a switch, each user may prefer the other to switch first. As a result, switching may be delayed" (Farrell and Saloner 1986, p. 943).

17 The rapid information dissemination provided by social media, thus, does not necessarily facilitate a switch to superior equilibria.
} 
be a coordination game, and the situation where all or most kids are biking or walking to school may be a mutually preferable equilibrium to the current one. But how to get there?

First, any policies making car transportation to school relatively unattractive, or even infeasible-e.g., prohibiting car traffic in the school's close neighborhood during start and end times - can make the current situation cease to be an equilibrium. Driving becomes expensive or impractical, while biking and walking becomes safer. If the situation in which most kids bike or walk is indeed a stable Nash equilibrium, it is self-enforcing, and even a temporary traffic ban can do the job.

Alternatively, the school headmaster may inform all parents that from next week on, all students are expected to bike or walk to school. Parents' driving is strongly discouraged; instead, the school organizes biking and walking groups, making sure that at least one parent participates in each group until new traffic patterns are firmly established. The latter not only protects kids' safety, but also makes deviant behavior easily observable, allowing for social sanctions. If the biking/walking solution is indeed a Nash equilibrium, the headmasters' message may suffice to change parents' driving behaviors permanently-provided that the message is perceived as authoritative enough that individuals expect others to follow the advice.

A formal analysis of mechanisms potentially moving the economy from one equilibrium to another requires an explicitly dynamic model, and goes beyond the scope of the present article. Some insight, however, can still be gained from simple comparative statics. Returning to the stylized model above, assume that Eq. (8) holds, and that the economy is currently in the brown equilibrium. A simple but drastic measure would be to prohibit the brown alternative or mandate the green one, leaving individuals with no choice but to coordinate on the green equilibrium. Alternatively, one may change incentives. Net material $\operatorname{costs} c^{g}$ and/or $c^{b}$ can be changed through instruments such as subsidies, taxes, and tradeable permits; the socially unconditional benefits $G^{0}$ and/or $B^{0}$ could possibly be influenced through policies such as infrastructure or $R \& D$ investments (bike lanes, speed bumps in the road, improved battery technology). If incentives are changed sufficiently that Eq. (6) still holds while Eq. (7) does not, there is no longer a brown equilibrium in the model: although the brown alternative is still permitted, it is no longer individually optimal even if everybody else is expected to choose it. Regardless of the policy instruments used, temporary policies may be sufficient: once the economy has settled in the green Nash equilibrium, noone has reason to deviate from it. ${ }^{18}$

As illustrated by the story of the headmasters' message, an economy may switch to a different social coordination equilibrium even if neither incentives nor the choice set have been altered-if otherwise self-fulfilling expectations can somehow be changed. Credible and authoritative information may sometimes suffice, such as an unenforced law, a coordinating message, or an information campaign. ${ }^{19}$ Infrastructure investments can serve as a commitment that a policy will prevail (Nyborg et al. 2016): a network of bike lanes, for example, is unlikely to be demolished once it has been established. Moreover, instruments

\footnotetext{
18 In general, the optimal choice between policy instruments tend to depend on factors such as cost and preference heterogeneity and asymmetric information, all of which are ignored in the present model; thus, the model is not well suited to explore this issue.

19 Note that information campaigns describing others' current behaviors may backfire (Andreoni et al. 2020): if the majority choice is currently brown, information emphasizing this will tend to reinforce the existing behavior.
} 
such as taxes, subsidies, and standards may affect expectations of others' behavior, since others' incentives are known to be changed as well as one's own (Nyborg et al. 2016).

Changing expectations is no straightforward task, however. An interesting example is that of smoking norms. In the model of Nyborg and Rege (2003), the smoking regulation introduced in public places is assumed to be strictly enforced; this ensures that the formal regulation makes non-smokers less used to passive smoking, thus setting off the chain reaction needed to flip the norm against indoor smoking even in private homes. However, the Norwegian 1988 smoking law amendment was not, in fact, strictly enforced by formal means. Although the following argument is somewhat speculative, it might be that the regulation rather strengthened smokers' expectations of being socially sanctioned for indoor smoking, particularly in regulated areas-and that this changed actual behaviors sufficiently to set off the required snowballing effect. In Greece, on the other hand, the introduction of an unenforced smoking regulation in 2010 appeared to have only minor and temporary effects (Vardavas et al. 2013), consistent with smokers' initial expectations of social sanctions being insufficiently affected (Nyborg et al. 2016). Perhaps Norwegians trust their government, and thus accept its announced intentions as authoritative, to a greater degree than Greeks do.

Note that I make no presumption that public policies can, or should, encourage social stigmatization as such. Rather, I have taken as given the potential existence of multiple equilibria, discussing how policy may influence which equilibrium is selected. In my formal model, the parameters $K$ and $k$ were treated as fixed, not affected by policy. In practice, however, policy may target drivers of coordination benefits even if one does not wish to encourage stigmatization: for example, a publicly financed network of charging stations for electric cars would make the benefits of owning an electric car less dependent of others' behavior (increasing $G^{0}$ while correspondingly reducing $K$ ).

Finally, one more word of caution: in my model, there are only two pure strategy options. In the real world, specifying all relevant alternatives can be hard. If some alternatives are overlooked, the game might have other stable Nash equilibria than the analyst foresees. Disrupting the current equilibrium could then lead the economy to coordinate in unexpected, not necessarily welfare improving ways. In practice, economic systems are not fully predictable; like ecological systems, they should be handled with care.

\section{Conclusions}

Both market and non-market exchanges are shaped by the social nature of human life. In particular, when the individual benefit of adopting a behavior increases sufficiently in others' adoption of the same behavior, multiple coordination equilibria can arise. Environmental impacts may differ substantially between these equilibria. If so, which equilibrium the economy coordinates on can be crucial for environmental quality.

A potentially important role for environmental policy is to help economic agents coordinate in environment-friendly ways. To induce tipping to a different equilibrium, incentives such as taxes or subsidies can be used to make the current situation temporarily cease to be an equilibrium. Alternatively, a policy might tip the economy by changing prevailing expectations about others behaviors and social feedbacks-but since expectations are largely a psychological phenomenon, this approach is less straightforward.

When confronted with an environmental problem, the following four questions may be helpful. Is the current situation likely to represent one equilibrium of a coordination game? 
If yes, is there a socially preferable equilibrium? If so, what policies could help push the economy past the tipping point? Finally, considering all expected costs and benefits, would the endeavor be worthwhile?

Multiplicity of equilibria may arise due to practical and logistical concerns (travelling to those conferences others in one's research field are likely to attend); social sanctions (nonsmokers reacting more negatively to indoor smoking if they are less used to it); infrastructure and/or network effects (bike lanes making people bike more, in turn increasing political support for improving the network of bike lanes). Multiple equilibria can also arise due to more complex and/or indirect mechanisms, such as society-wide cultures of trust or mistrust, corruption or honesty (Basu 2000, Ch. 5.2; Tabellini 2008), providing selfreinforcing political support to policies such as wide-reaching or minimal welfare states (Benabou and Tirole 2006; Lindbeck et al. 1999).

Compared to the simple model of identical individuals presented above, individual heterogeneity narrows the conditions under which multiple equilibria arise (Efferson et al. 2020). Nevertheless, given the fundamental social nature of human interaction, my guess is that there exist many more examples of environmentally relevant social coordination than those mentioned here. If further examples are hard to think of, the very stability of coordination equilibria may be one reason: "standard" examples such as smoking norms may come more easily to mind precisely because they represent cases where widespread customary behaviors have recently switched - an otherwise relatively rare phenomenon. When exploring the potential of environmental policy as coordination tool, then, economists may need not only theoretical insight and empirical knowledge-but also a healthy dose of creative imagination.

Acknowledgements Open Access funding provided by University of Oslo (incl Oslo University Hospital). This paper is partly based on my David Pearce Lecture at the 23rd Annual Meeting of the European Association of Environmental and Resource Economists in Athens, June 30, 2017. I am grateful to the ERE Editors for encouraging me to write a journal article based on the talk. Thanks also to the Beijer Institute of Ecological Economics for sponsoring the artwork in Figs. 1 and 2, to artist and copyright holder Elsa Wikander, Azote, for permission to use these figures, and to Geir Asheim, Kjell Arne Brekke and a reviewer for helpful comments and suggestions. The author is part of CREE, Oslo Centre for Research on Environmentally friendly Energy, sponsored by the Research Council of Norway (RCN Grant No. 209698).

Open Access This article is licensed under a Creative Commons Attribution 4.0 International License, which permits use, sharing, adaptation, distribution and reproduction in any medium or format, as long as you give appropriate credit to the original author(s) and the source, provide a link to the Creative Commons licence, and indicate if changes were made. The images or other third party material in this article are included in the article's Creative Commons licence, unless indicated otherwise in a credit line to the material. If material is not included in the article's Creative Commons licence and your intended use is not permitted by statutory regulation or exceeds the permitted use, you will need to obtain permission directly from the copyright holder. To view a copy of this licence, visit http://creativecommons.org/licenses/by/4.0/.

\section{References}

Allcott H (2011) Social norms and energy conservation. J Public Econ 95(5):1982-2095

Andreoni J, Nikiforakis N, Siegenthaler S (2020) Predicting social tipping and norm change in controlled experiments (Unpublished working paper)

Basu K (2000) Prelude to political economy: a study of the social and political foundations of economics. Oxford University Press, Oxford

Benabou R, Tirole J (2006) Belief in a just world and redistributive politics. Quart J Econ 121(2):699-746 
Berkman LF, Syme SL (1979) Social networks, host resistance, and mortality: a nine-year follow-up study of Alameda County residents. Am J Epidemiol 109:186-204

Bicchieri C (2006) The grammar of society: the nature and dynamics of social norms. Cambridge University Press, Cambridge

Brekke KA, Kipperberg G, Nyborg K (2010) Social interaction in responsibility ascription: the case of household recycling. Land Economics 86(4):766-784

Carattini S, Levin S, Tavoni A (2017) Cooperation in the climate commons. Grantham Research Institute on Climate Change and the Environment Working Paper No. 259

Cialdini RB, Kallgren CA, Reno RR (1991) A focus theory of normative conduct: a theoretical refinement and reevaluation of the role of norms in human behavior. Adv Exp Soc Psychol 24:201-234

Czajkowski M, Hanley N, Nyborg K (2017) Social norms, morals and self-interest as determinants of proenvironment behaviours: the case of household recycling. Environ Resource Econ 66:647-670

Dasgupta P, Ehrlich R (2013) Pervasive externalities at the population, consumption, and environment nexus. Science 340:324-328

Dasgupta P, Southerton D, Ulph A, Ulph D (2016) Consumer behaviour with environmental and social externalities: implications for analysis and policy. Environ Resource Econ 65(1):191-226

Donne J (1624) Devotions upon Emergent Occasions and seuerall steps in my Sicknes. London: A. M. for Thomas Iones. (Web edition published by eBooks@ Adelaide; Adelaide: University of Adelaide 2014, https://ebooks.adelaide.edu.au/d/donne/john/devotions/. Accessed June 2017

Efferson C, Vogt S, Fehr E (2020) The promise and the peril of using social influence to reverse harmful traditions. Nat Hum Behav 4:55-68

Eisenberger NI, Muscatell KA (2013) The pleasures and pains of social interactions: a social cognitive neuroscience perspective. In: The oxford handbook of cognitive neuroscience, volume 2: the cutting edges. Edited by Kevin N. Ochsner and Stephen Kosslyn

Eisenberger NI, Lieberman MD, Williams KD (2003) Does rejection hurt? An fMRI study of social exclusion. Science 302(5643):290-292

Farrell J, Saloner G (1985) Standardization, compatibility, and innovation. RAND J Econ 16:70-83

Farrell J, Saloner G (1986) Innovation, product preannouncements, and predation. Am Econ Rev 76(5):940-955

Farrow K, Grolleau G, Ibanez L (2017) Social norms and pro-environmental behavior: a review of the evidence. Ecol Econ 140:1-13

Gintis H (2010) Social norms as choreography. Polit Philos Econ 9(3):251-264

Goldberger L (1966) Experimental isolation: an overview. Am J Psychiat 122:774-782

Greaker M, Midttømme K (2016) Optimal environmental policy with network effects: will Pigouvian taxation lead to excess inertia? J Public Econ 143:27-38

House JS, Landis KR, Umberson D (1988) Social relationships and health. Science 241:540-545

Johansson-Stenman O, Martinsson P (2006) Honestly, why are you driving a BMW? J Econ Behav Organ 60:129-146

Klemperer P (2008) Network goods (theory). In: Palgrave Macmillan (eds) The new Palgrave dictionary of economics. Palgrave Macmillan, London

Lieberman MD (2013) Social. Why our brains are wired to connect. Crown Publishers, New York

Liebowitz SJ, Margolis SE (1994) Network externality: an uncommon tragedy. J Econ Perspect $8(2): 133-150$

Lindbeck A, Nyberg S, Weibull JW (1999) Social norms and economic incentives in the welfare state. Quart J Econ 114(1):1-35

Nyborg K (2018) Social norms and the environment. Annu Rev Resource Econ 10:405-423. https://doi. org/10.1146/annurev-resource-100517-023232

Nyborg K (2019) The third theorem of welfare economics: report from a fictional field study. IZA DP No. 12269, Bonn

Nyborg K, Rege M (2003) On social norms: the evolution of considerate smoking behavior. J Econ Behav Organ 52:323-340

Nyborg K, Howarth RB, Brekke KA (2006) Green consumers and public policy: on socially contingent moral motivation. Resour Energy Econ 28(4):351-366

Nyborg K, Anderies JM, Dannenberg A, Lindahl T, Schill C, Schlüter M, Adger WN, Arrow KJ, Barrett S, Carpenter S, Chapin FS III, Crépin A-S, Daily G, Ehrlich P, Folke C, Jager W, Kautsky N, Levin SA, Madsen OJ, Polasky S, Scheffer M, Walker B, Weber EU, Wilen J, Xepapadeas A, de Zeeuw A (2016) Social norms as solutions. Science 354(6308):42-43. https://doi.org/10.1126/science.aaf8317

Ostrom E (1990) Governing the commons: the evolution of institutions for collective action. Cambridge University Press, Cambridge

Oswald A (1997) Happiness and economic performance. Econ J 107(445):1815-1831 
Pal R, Banerjee P, Wossink A (2017) Going green to be seen: the case of biodiversity protection on farmland. University of Manchester Economics Discussion Paper EDP-1701

Rege M (2004) Social norms and private provision of public goods. J Public Econ Theory 6(1):65-77

Richter A, Grasman J (2013) The transmission of sustainable harvesting norms when agents are conditionally cooperative. Ecol Econ 93:202-209

Ringach DL (2009) Spontaneous and driven cortical activity: implications for computation. Curr Opin Neurobiol 19(4):439-444

Schelling TC (1960) The strategy of conflict. Harvard University Press, Cambridge

Schlüter M, Tavoni A, Levin S (2016) Robustness of norm-driven cooperation in the commons. Proc R Soc B 283:20152431. https://doi.org/10.1098/rspb.2015.2431

Sireteanu R, Oertel V, Mohr H, Linden D, Singer W (2008) Graphical illustration and functional neuroimaging of visual hallucinations during prolonged blindfolding: a comparison to visual imagery. Perception 37(12):1805-1821

Sugden R (1989) Spontaneous order. J Econ Perspect 3-4:85-97

Tabellini G (2008) The scope of cooperation: values and incentives. Quart J Econ 123(3):905-950

Umberson D, Wortman CB, Kessler RC (1992) Widowhood and depression: explaining long-term gender differences in vulnerability. J Health Soc Behav 33(1):10-24

Vardavas CI, Agaku I, Patelarou E, Anagnostopoulos N, Nakou C, Dramba V et al (2013) Ashtrays and signage as determinants of a smoke-free legislation's success. PLoS ONE 8(9):e72945. https://doi. org/10.1371/journal.pone.0072945

Weibull J (1995) Evolutionary game theory. MIT Press, Cambridge

Young HP (1996) The economics of convention. J Econ Perspect 10(2):105-122

Young HP (1998) Social norms and economic welfare. Eur Econ Rev 42:821-830

Young HP (2015) The evolution of social norms. Annu Rev Econ 7:359-387

Zuckerman M, Cohen N (1964) Sources of reports of visual auditory sensations in perceptual-isolation experiments. Psychol Bull 62(1):1-20

Publisher's Note Springer Nature remains neutral with regard to jurisdictional claims in published maps and institutional affiliations. 